\title{
Structure Modification of an Active Azo-Compound as a Route to New Antimicrobial Compounds
}

\author{
Simona Concilio ${ }^{1, *}$, Lucia Sessa ${ }^{2}$, Anna Maria Petrone ${ }^{2,3}$, Amalia Porta ${ }^{2}$, Rosita Diana ${ }^{4}$, \\ Pio Iannelli ${ }^{2}$ and Stefano Piotto ${ }^{2}$ \\ 1 Department of Industrial Engineering, University of Salerno, Via Giovanni Paolo II 132, 84084 Fisciano, Italy \\ 2 Department of Pharmacy, University of Salerno, Via Giovanni Paolo II 132, 84084 Fisciano, Italy; \\ lucsessa@unisa.it (L.S.); Anpetrone@unisa.it (A.M.P.); aporta@unisa.it (A.P.); piannelli@unisa.it (P.I.); \\ piotto@unisa.it (S.P.) \\ 3 PhD Program in Drug Discovery and Development, University of Salerno, Via Giovanni Paolo II 132, \\ 84084 Fisciano, Italy \\ 4 Department of Chemical Science, University of Napoli “Federico II”, Cupa Nuova Cintia 21, 80126 Napoli, \\ Italy; rosita.diana@libero.it \\ * Correspondence: sconcilio@unisa.it; Tel.: +39-089-964-115
}

Academic Editors: Krasimir Vasilev, Alex Cavallaro and Peter Zilm

Received: 4 May 2017; Accepted: 22 May 2017; Published: 25 May 2017

\begin{abstract}
Some novel (phenyl-diazenyl)phenols 3a-g were designed and synthesized to be evaluated for their antimicrobial activity. A previously synthesized molecule, active against bacteria and fungi, was used as lead for modifications and optimization of the structure, by introduction/removal or displacement of hydroxyl groups on the azobenzene rings. The aim of this work was to evaluate the consequent changes of the antimicrobial activity and to validate the hypothesis that, for these compounds, a plausible mechanism could involve an interaction with protein receptors, rather than an interaction with membrane. All newly synthesized compounds were analyzed by ${ }^{1} \mathrm{H}-\mathrm{NMR}$, DSC thermal analysis and UV-Vis spectroscopy. The in vitro minimal inhibitory concentrations (MIC) of each compound was determined against Gram-positive and Gram-negative bacteria and Candida albicans. Compounds $\mathbf{3} \mathbf{b}$ and $\mathbf{3 g}$ showed the highest activity against $S$. aureus and C. albicans, with remarkable MIC values of $10 \mu \mathrm{g} / \mathrm{mL}$ and $3 \mu \mathrm{g} / \mathrm{mL}$, respectively. Structure-activity relationship studies were capable to rationalize the effect of different substitutions on the phenyl ring of the azobenzene on antimicrobial activity.
\end{abstract}

Keywords: azo-compound; antimicrobial; synthesis; QSAR

\section{Introduction}

Antimicrobial therapy is a powerful tool for the treatment of several diseases, and is a keystone of modern medicinal practice. Infections by pathogenic microorganisms are of great concern in many fields, particularly in medical devices, hospital surfaces, surgery equipment, health care products, food packaging and storage. Infections are generally combated with antimicrobial agents [1], however, some bacteria, upon mutating their genes, have become resistant to common antibiotics and this makes difficult their elimination [2-6]. Consequently, the increased resistance of microorganisms to the currently used antimicrobials has led to the evaluation of other agents that might have antimicrobial activity $[7,8]$.

Recently, our research group described the synthesis and properties of some azobenzene-based compounds and their antimicrobial properties both as single molecules [9] and dispersed in a polymer matrix [10-12]. In one of these works, we also selected the best candidates by preliminary in-silico test of ADMET properties and then we synthesized the azo compounds with lowest in-silico toxicity 
values according to the classic diazo coupling reaction scheme $[9,13]$. The majority of synthesized compounds exhibited high antibacterial activity against $S$. aureus and antifungal activity against C. albicans, but they were inactive against Gram-negative bacteria such as Pseudomonas aeruginosa and Salmonella typhimurium. Because of the structural similarity with stilbenes, these compounds can share a similar mechanism of action. They could inhibit ATP synthase binding at the interface between $\alpha$ and $\gamma$ subunits [9].

Azobenzene-based derivatives possess interesting features that warrant further investigation. Among others, the presence of photo-inducible isomerism can be exploited in remodeling lipid membranes [14] or to modulate the membrane interaction of peptides [15]. Currently, we are evaluating the possibility to exploit azobenzene-based derivatives to synthesize tunable metal complexes $[16,17]$ having antimicrobial activity.

In this work, we introduced some structure modifications to enhance the biological activity of the previously obtained azo-compounds. In particular, we aimed to evaluate the change in activity related to different types of substituents linked on the azobenzene structure.

We chose compound A4 from [9], one the best antibacterial azo-compound we synthesized, as lead compound to synthesize several analogues (see Figure 1). We introduced simple molecular modifications on both azobenzene rings, in order to evaluate the role of the phenolic hydroxyl group in the mechanism of action. The substituents are joined to the fixed moiety azobenzene: the modifications involved moving of the phenolic hydroxyl group from the para- to the meta-position, or removal of the phenolic hydroxyl group, and replacing the phenolic hydroxyl group by methoxy and methyl groups, to study and compare their antimicrobial activity.

Quantitative Structure-Activity Relationships (QSAR) are mathematical frameworks that relate the molecular structures of compounds with their natural activities in a quantitative way [7]. The main success of the QSAR method is the possibility to estimate the properties of new chemical compounds without the need to synthesize and test them. One of the most efficient and popular technique is the Genetic Algorithm Search (GAS). GAS are inspired by natural evolution principles where variables play the role of genes (in this case a set of descriptors) in an individual of the species. A group of random individuals (population) evolves according to a fitness function (in this case the antimicrobial activity) that determines the persistence of the individuals. The algorithm exploits selection, mutation, and crossover operations on the genes. The QSAR correlates biological activity with structural and chemical properties. The results of the QSAR analysis permitted to develop a model of activity in which electronics transition are crucial. This approach will permit a more efficient design of azobenzene-based antibiotics.

\section{Results and Discussion}

\subsection{Chemistry}

The substituted-(phenyldiazenyl)phenols 3a-g derivatives are reported in Figure 1.

\begin{tabular}{rccccc}
\hline & $\mathbf{R}_{\mathbf{1}}$ & $\mathbf{R}_{\mathbf{2}}$ & $\mathbf{R}_{\mathbf{3}}$ & $\mathbf{R}_{\mathbf{4}}$ & $\mathbf{R}_{\mathbf{5}}$ \\
\hline $\mathbf{A 4}$ (lead) & $\mathrm{OH}$ & $\mathrm{H}$ & $\mathrm{CH}_{3}$ & $\mathrm{OH}$ & $\mathrm{CH}_{3}$ \\
$\mathbf{3 a}$ & $\mathrm{H}$ & $\mathrm{OH}$ & $\mathrm{CH}_{3}$ & $\mathrm{OH}$ & $\mathrm{CH}_{3}$ \\
$\mathbf{3 b}$ & $\mathrm{H}$ & $\mathbf{H}$ & $\mathrm{CH}_{3}$ & $\mathrm{OH}$ & $\mathrm{CH}_{3}$ \\
$\mathbf{3 c}$ & $\mathrm{OCH}_{3}$ & $\mathrm{H}$ & $\mathrm{CH}_{3}$ & $\mathrm{OH}$ & $\mathrm{CH}_{3}$ \\
$\mathbf{3 d}$ & $\mathrm{CH}_{3}$ & $\mathrm{H}$ & $\mathrm{CH}_{3}$ & $\mathrm{OH}$ & $\mathrm{CH}_{3}$ \\
$\mathbf{3 e}$ & $\mathrm{OH}$ & $\mathrm{H}$ & $\mathrm{H}$ & $\mathbf{H}$ & $\mathbf{H}$ \\
$\mathbf{3 f}$ & $\mathrm{OH}$ & $\mathbf{H}$ & $\mathrm{H}$ & $\mathrm{OCH}_{3}$ & $\mathrm{H}$ \\
$\mathbf{3 g}$ & $\mathrm{OH}$ & $\mathrm{H}$ & $\mathrm{H}$ & $\mathrm{CH}_{3}$ & $\mathrm{H}$ \\
\hline
\end{tabular}

Figure 1. Substituted-(phenyldiazenyl)phenol derivatives 3a-g. 
All derivatives 3a-g were synthesized according to the methods outlined in Schemes 1 and 2.<smiles>[R]c1ccc(N)cc1[R]</smiles>

1<smiles>[R]c1ccc(N=Nc2cc(C)c(O)c(C)c2)cc1[R]</smiles>

3a-d<smiles>[NH3+]c1ccc(O)cc1</smiles>

2

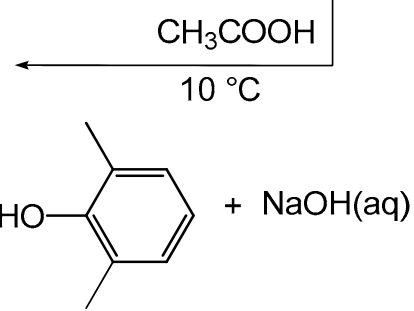

Scheme 1. Synthetic route for compounds 3a-d.<smiles>[R]c1ccc(N)cc1</smiles>

1

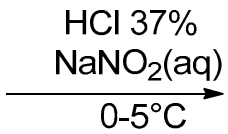

$0-5^{\circ} \mathrm{C}^{2}$<smiles>[N+]c1ccc(O)cc1</smiles>

2

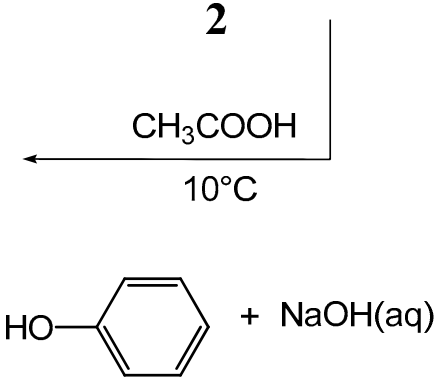

Scheme 2. Synthetic route for compounds $3 \mathbf{e}-\mathbf{g}$.

Synthesis of compounds 3a-g was accomplished according to the classic diazo coupling reaction scheme. An aromatic amine $\mathbf{1}$ (depending on the A4 analogue) was suspended in an acid solution and cooled in an ice bath. Sodium nitrite was added, obtaining a suspension of the diazonium salt 2. Separately, an aqueous solution of $\mathrm{NaOH}$ containing the appropriate phenol was prepared and the two solutions mixed under stirring, maintaining the $\mathrm{pH}$ values around 10 for $30 \mathrm{~min}$. The final solution was acidified until a dark red precipitate of the azo compound was formed. ${ }^{1} \mathrm{H}-\mathrm{NMR}$ experiments were performed to confirm all structures.

\subsection{Thermal and Optical Properties}

In Table 1, the thermal and optical properties of the synthesized compounds are reported. Analogues $3 \mathbf{a}, \mathbf{3} \mathbf{b}, \mathbf{3 d}$ and $\mathbf{3 e}$ showed only a melting peak in the first heating run and they were not able to crystallize from the melt. In particular, $3 a$ melts at $114.4^{\circ} \mathrm{C}, 3 \mathrm{~b}$ at $87.7^{\circ} \mathrm{C}, 3 \mathrm{~d}$ at $89.3^{\circ} \mathrm{C}$ and $162.0^{\circ} \mathrm{C}$. Compound $3 \mathrm{c}$ showed a sharp melting peak in the first heating run at $128.3^{\circ} \mathrm{C}$ and a crystallization peak at $94.6^{\circ} \mathrm{C}$ in the cooling run. When heated in the second run, it showed the same melting peak as in the first run. Compound $3 f$ showed a sharp melting peak in the first heating run at $147.3^{\circ} \mathrm{C}$ and a crystallization peak at $110.6{ }^{\circ} \mathrm{C}$ in the cooling run; when heated in the second run, it showed the same melting peak as in the first run. $3 \mathrm{~g}$ showed a sharp melting peak in the first heating run at $158.7^{\circ} \mathrm{C}$ 
and a crystallization peak at $90.7^{\circ} \mathrm{C}$ in the cooling run. When heated in the second run, it showed the same melting peak as in the first run.

Table 1. Thermal and optical properties of compounds 3a-g.

\begin{tabular}{ccccccc}
\hline \multirow{2}{*}{ Molecule } & \multicolumn{3}{c}{ Thermal Characterization } & \multicolumn{2}{c}{ Optical Characterization } \\
\cline { 2 - 6 } & $\mathbf{T}_{\mathbf{m}}\left({ }^{\circ} \mathbf{C}\right)$ & $\left.\Delta \mathbf{H}_{\mathbf{m}} \mathbf{( J / g}\right)$ & $\mathbf{T}_{\mathbf{c}}\left({ }^{\circ} \mathbf{C}\right)$ & $\left.\Delta \mathbf{H}_{\mathbf{c}} \mathbf{J} / \mathbf{g}\right)$ & $\lambda_{\max }(\mathbf{n m})$ & $\varepsilon_{\max }\left(\mathbf{L ~ m o l}^{-\mathbf{1}} \mathbf{~ c m}^{-\mathbf{1}}\right)$ \\
\hline 3a & 114.4 & 5.7 & - & - & 358 & 9300 \\
3b & 87.7 & 78.0 & - & - & 344 & 18,300 \\
3c & 128.3 & 98.1 & 94.6 & 92.1 & 360 & 14,000 \\
3d & 89.3 & 86.1 & - & - & 354 & 11,400 \\
3e & 162.0 & 149.8 & - & - & 344 & 14,470 \\
3f & 147.3 & 123.3 & 110.6 & 104.5 & 355 & 14,200 \\
3g & 158.7 & 139.4 & 90.7 & 83.7 & 358 & 14,350 \\
\hline
\end{tabular}

$\mathrm{T}_{\mathrm{m}}=$ melting temperature, from DSC analysis, $10^{\circ} \mathrm{C} / \mathrm{min}$, nitrogen flow; $\mathrm{T}_{\mathrm{c}}=$ crystallization temperature, from DSC cooling run; Instrument error $\pm 0.5^{\circ} \mathrm{C} . \Delta \mathrm{H}_{\mathrm{m}} / \Delta \mathrm{H}_{\mathrm{c}}=$ melting/crystallization enthalpy, evaluated by integration of the peak. Experimental error $\pm 5 \%$. $\lambda_{\max }=$ wavelength at the principal absorption maximum, $\varepsilon_{\max }=$ molar extinction coefficient at absorption maximum.

The spectral region 650-240 nm was investigated by UV-Vis spectrophotometry, at a concentration of about $3.0 \times 10^{-5} \mathrm{~mol} \mathrm{~L}^{-1}$ of azo-compound in acetonitrile solution (Table 1). The UV-visible spectra for $3 \mathbf{a}-\mathbf{g}$ are qualitatively only depend on the azobenzene unit, which is the same for all compounds. The UV absorption spectra of A4 analogues in trans configuration, showed the typical absorption bands of the electronic transitions of the azobenzene chromophore [18].

\subsection{Antimicrobial Activity}

The MICs of the synthesized analogues and of lead compound A4 were determined by the microbroth dilution for S. aureus A170, P. aeruginosa ATCC-27853 strains and C. albicans SC5314 (Table 2).

Table 2. Antimicrobial and antifungal activity of A4 analogues. Geometric mean MICs $(\mu \mathrm{g} / \mathrm{mL})$ after $24 \mathrm{~h}$.

\begin{tabular}{cccc}
\hline \multirow{2}{*}{ Molecule } & S. aureus & P. aeruginosa & C. albicans \\
\cline { 2 - 4 } & \multicolumn{2}{c}{ MIC $_{\mathbf{5 0}}$} & $\mathrm{MIC}_{\mathbf{2}}$ \\
\hline A4 (lead) & $15\left(\mathrm{MIC}_{100} 20^{*}\right)$ & $>35$ & $15\left(\mathrm{MIC}_{0} 17^{*}\right)$ \\
3a & 30 & $>35$ & 25 \\
3b & $7\left(\mathrm{MIC}_{100} 10\right)$ & $>35$ & 10 \\
3c & $>35$ & $>35$ & $>35$ \\
3d & $>35$ & $>35$ & $>35$ \\
3e & 25 & $>35$ & 20 \\
3f & 25 & $>35$ & 25 \\
3g & $7\left(\mathrm{MIC}_{100} 20\right)$ & $>35$ & $\mathrm{MIC}_{0} 3$ \\
\hline
\end{tabular}

$\mathrm{MIC}_{50}$ : Minimum Inhibitory Concentration required to inhibit the growth of $50 \%$ of bacteria. $\mathrm{MIC}_{100}$ : Minimum Inhibitory Concentration required to inhibit the growth of $100 \%$ of bacteria. $\mathrm{MIC}_{2}$ : Minimum Inhibitory Concentration required to inhibit the growth of $50 \%$ of fungus. $\mathrm{MIC}_{0}$ : Minimum Inhibitory Concentration required to inhibit the growth of $100 \%$ of fungus. The values are the geometric mean of at least three determinations. ${ }^{*}$ Data from ref. [9].

Analogues $\mathbf{3 b}$ and $\mathbf{3 g}$ are the most active antimicrobial analogue, exhibiting activity at a concentration lower than the lead compound concentration. In particular, $\mathbf{3 b}$ is the only analogue able to inhibit the growth of $100 \%$ of $S$. aureus at a concentration of $10 \mu \mathrm{g} / \mathrm{mL}$; indeed for other compounds only the $\mathrm{MIC}_{50}$ values are reported (Table 2). Compound $\mathbf{3 g}$ is the most active antifungal analogue, showing an $\mathrm{MIC}_{0}$, which means $100 \%$ of inhibition of C. albicans duplication already at $3 \mu \mathrm{g} / \mathrm{mL}$ (see also Figure 2).

Compared to the reference molecule, other analogues such as $\mathbf{3 a}, \mathbf{3 e}$ and $\mathbf{3 f}$ show lower activities. Nevertheless, they still possess antimicrobial and antifungal activity, even if at concentrations higher than A4. Compounds $\mathbf{3 c}$ and $\mathbf{3 d}$ lose the antibacterial and antifungal activity and none of the analogues 
exhibit antimicrobial activity against $P$. aeruginosa, as already observed for previously synthesized similar compounds [9].

Interestingly, all the compounds show antibacterial activity only against Gram-positive bacteria. This can be correlated with the different composition and structure of the Gram-negative bacteria. Figure 2 shows the total inhibition of germination and hyphae formation of azo compound $\mathbf{3 g}$ on C. albicans, at $3 \mu \mathrm{g} / \mathrm{mL}$. In the absence of azo compound, an extensive hyphae formation was observed, whereas when $\mathbf{3} \mathbf{g}$ was present, hyphae formation was severely hampered in a concentration-dependent manner.
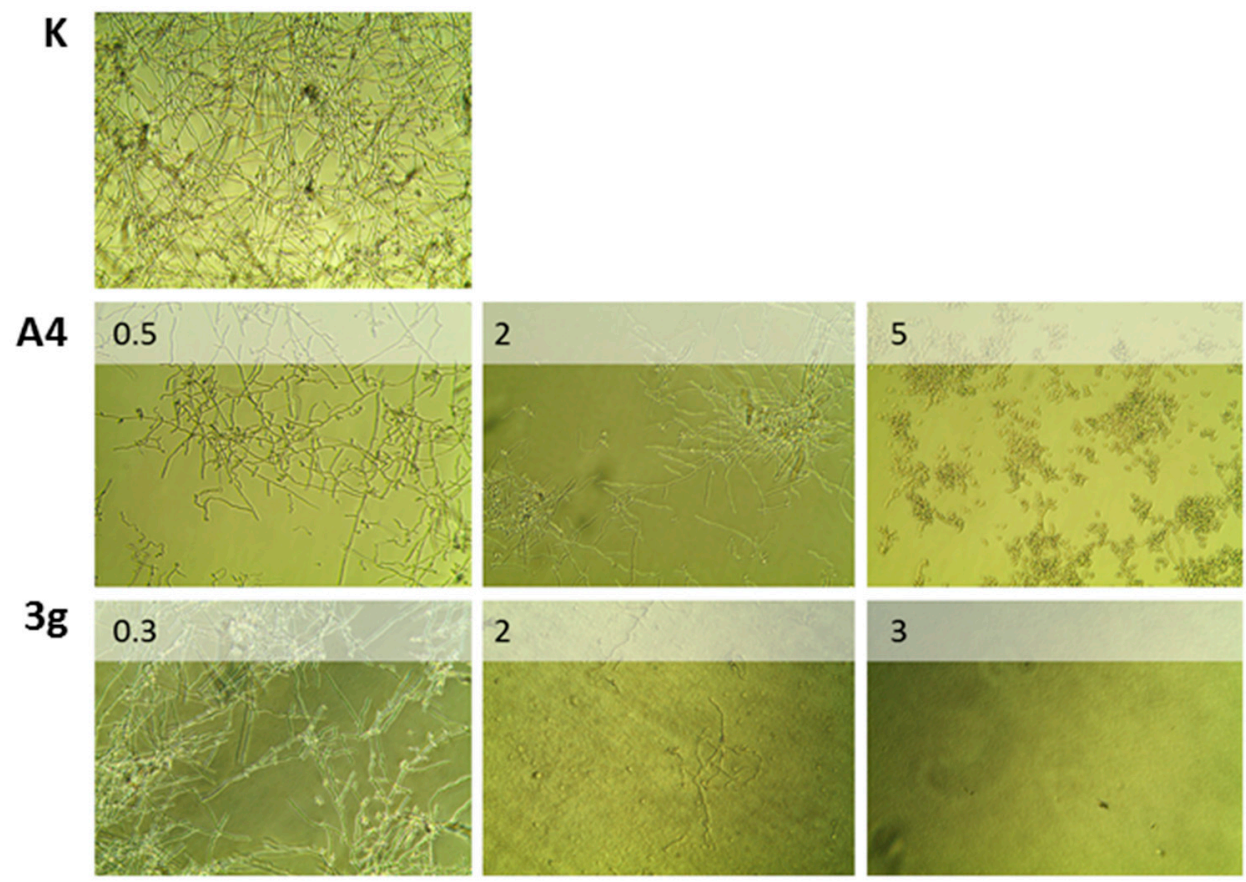

Figure 2. Inhibition of hyphae formation in Candida albicans at different concentrations $(\mu \mathrm{g} / \mathrm{mL})$ of $\mathbf{A 4}$ and $3 g$ (20× optical zoom).

\subsection{QSAR Models}

QSAR models were performed to predict the activity of azobenzene molecules against S. aureus. We have generated several QSAR models using different training and test sets and we have retained only statistically significant models. The efficacy of the molecules are estimated as the inverse of $\mathrm{MIC}_{50}$. Therefore, higher efficacy corresponds to higher values of $1 / \mathrm{MIC}_{50}$. After careful evaluation of all models, we have chosen the following:

$$
\frac{1}{\mathrm{MIC}_{50}}=0.0789 \cdot \mathrm{VR} 1_{\mathrm{Dzp}}-0.0580 \cdot \mathrm{SpMin} 8_{B h i}+0.116
$$

where VR1_Dzp is the Randic-like eigenvector-based index from Barysz matrix/weighted by polarizabilities and standardized by range, and SpMin8_Bhi is the smallest absolute eigenvalue of Burden modified matrix $-\mathrm{n} 8$ / weighted by relative first ionization potential standardized by range.

These descriptors belong to the Barysz distance matrix-based descriptors, and to the Burden modified matrix. The best model correlates polarizabilities and ionization potential with the biocidal activity and, therefore, suggests an interaction with a protein receptor rather than with the bacterial cell membrane. The comparison between the experimental biocidal activity against $S$. aureus and the predicted $\mathrm{MIC}_{50}$ calculated with Equation (1) is shown in Table 3. 
Table 3. Comparison of experimental and calculated antimicrobial activity against S. aureus.

\begin{tabular}{ccccccc}
\hline Molecule & $\begin{array}{c}\mathbf{M I C}_{\mathbf{5 0}} \\
\text { Experimental } \\
(\boldsymbol{\mu g} / \mathbf{m L})\end{array}$ & $\begin{array}{c}\text { Actual } \\
\text { Values for } \\
\text { C:1/MIC }\end{array}$ & ALogP & $\begin{array}{c}\text { Equation (1): } \\
\text { Predicted } \\
\text { Values }\end{array}$ & $\begin{array}{c}\text { Equation (1): } \\
\text { Residual } \\
\text { Values }\end{array}$ & $\begin{array}{c}\text { MIC }_{\mathbf{5 0}} \\
\text { Predicted }\end{array}$ \\
\hline A4 & 15 & 0.067 & 2.8 & 0.0513 & 0.0154 & 19 \\
3a & 30 & 0.033 & 2.8 & 0.0520 & -0.0187 & 19 \\
3b & 7 & 0.143 & 5.0 & 0.1460 & -0.0030 & 7 \\
3c & $80^{*}$ & 0.013 & 3.0 & 0.0214 & -0.0089 & 50 \\
3d & $80 *$ & 0.013 & 7.2 & 0.0357 & -0.0232 & 30 \\
3e & 25 & 0.040 & 1.8 & 0.0452 & -0.0052 & 22 \\
3f & 25 & 0.040 & 0.7 & 0.0909 & -0.0509 & 11 \\
3g & 7 & 0.143 & 3.2 & 0.0950 & 0.0479 & 10 \\
A1 & 17 & 0.059 & 0.8 & 0.0756 & -0.0168 & 13 \\
A2 & 15 & 0.067 & 2.6 & 0.0822 & 0.0155 & 12 \\
A3 & 14 & 0.071 & 0.2 & 0.0699 & 0.0015 & 14 \\
A5 & 18 & 0.056 & 4.3 & 0.0625 & -0.0069 & 16 \\
B10 & $80^{*}$ & 0.013 & 0.3 & 0.0142 & -0.0017 & 70 \\
B11 & $80^{*}$ & 0.013 & 1.1 & 0.0142 & -0.0017 & 70 \\
\hline
\end{tabular}

* Molecules that did not show activity for concentration larger than $35 \mu \mathrm{g} / \mathrm{mL}$, have been arbitrarily assigned to 80 to perform the GFA.

The validation tests used to check the predictive ability of the model are listed in Table 4 .

Table 4. Validation of the genetic function results.

\begin{tabular}{cc}
\hline Parameters & Value \\
\hline Friedman LOF & 0.00302 \\
R-squared & 0.802 \\
Adjusted R-squared & 0.766 \\
Cross validated R-squared & 0.654 \\
Significant Regression & Yes \\
Significance-of-regression F-value & 22.321 \\
Critical SOR F-value (95\%) & 5.2341 \\
Replicate points & 0 \\
Computed experimental error & 0.000 \\
Number or points for Lack-of-fit test & 11 \\
Min expt. error for non-significant LOF (95\%) & 0.0201 \\
\hline
\end{tabular}

The validation tests indicate good predictive capability of the model, but there are a few molecules showing a large error. In particular, molecule $3 \mathbf{d}$ displays the highest error. This could be associated to the low solubility of $\mathbf{3 d}$ that, in fact, has the largest value of $\mathrm{Alog}$. AlogP is a thermodynamic descriptor and represents hydrophobicity [19].

\section{Materials and Methods}

\subsection{General Information}

All the reagents and solvents were purchased from Sigma-Aldrich (Milan, Italy) and used without further purification. Optical observations were performed by using a Jenapol microscope (Zeiss S.p.A., Milano, Italy) fitted with a THMS 600 hot stage (Linkam, Waterfield, Epsom, Tadworth, UK). Phase transition temperatures and enthalpies were measured using a Pyris 1 DSC scanning calorimeter (PerkinElmer, Waltham, MA, USA) at a scanning rate of $10^{\circ} \mathrm{C} / \mathrm{min}$, under nitrogen flow. UV-Vis absorption spectra of the samples were recorded at $25^{\circ} \mathrm{C}$ in acetonitrile solution, on a Perkin Elmer Lambda 19 spectrophotometer. The spectral region $650-240 \mathrm{~nm}$ was investigated by using cell path length of $1.0 \mathrm{~cm}$. Azobenzene chromophore concentration of about $3.0 \times 10^{-5} \mathrm{~mol} \mathrm{~L}^{-1}$ was used. 
${ }^{1} \mathrm{H}-\mathrm{NMR}$ spectra were recorded with a DRX/400 spectrometer (Bruker, Billerica, MA, USA). Chemical shifts are reported relative to the residual solvent peak (dimethylsulfoxide- $d_{6}: H=2.50 \mathrm{ppm}$ ). HPLC runs were carried out on a $\mathrm{C}_{18}$ column (Jupiter, $5 \mu \mathrm{m}, 300 \AA$, LC column $150 \times 4.60 \mathrm{~mm}$, Phenomenex, Torrance, CA, USA) at a flow rate of $1.0 \mathrm{~mL} / \mathrm{min}$. The gradient [solution A: TFA (0.1\%); solution B: TFA $\left.(0.07 \%), \mathrm{H}_{2} \mathrm{O}(5 \%), \mathrm{CH}_{3} \mathrm{CN}(95 \%)\right]$ was $20-70 \%$ B over $20 \mathrm{~min}$. HPLC analysis was performed on an 1260 Infinity Series system (Agilent, Santa Clara, CA, USA) with UV detection at 280, 320, 350 and $380 \mathrm{~nm}$.

\subsection{General Method of the Synthesis of (Phenyl-Diazenyl)Phenols Derivatives 3a-d}

A suspension of the proper aromatic amine $(0.0183 \mathrm{~mol})$ in a solution containing water $(38 \mathrm{~mL})$ and $\mathrm{HCl} 37 \%(w / w, 4 \mathrm{~mL})$ was cooled at $0-5{ }^{\circ} \mathrm{C}$ in a water-ice bath. A solution of sodium nitrite $(1.39 \mathrm{~g}$, $0.0202 \mathrm{~mol})$ dissolved in water $(8.0 \mathrm{~mL})$ was added dropwise, giving a suspension of the diazonium salt (solution A). Separately, a solution containing $\mathrm{NaOH}(0.7 \mathrm{~g}, 0.0175 \mathrm{~mol})$ in water $(50 \mathrm{~mL})$ with 2,6-dimethylphenol ( $2.23 \mathrm{~g}, 0.0183 \mathrm{~mol}$ ) was prepared (solution B). Solution A was added dropwise to solution $\mathrm{B}$, under stirring at $12^{\circ} \mathrm{C}$. The system was left reacting for $30 \mathrm{~min}$, maintaining the $\mathrm{pH}=10-11$. Then the final solution was slowly added to $103 \mathrm{~mL}$ of an acid solution $(100 \mathrm{~mL}$ of water and $3 \mathrm{~mL}$ of acetic acid), and then stirred for $30 \mathrm{~min}$ at $15{ }^{\circ} \mathrm{C}$. A dark red precipitate of the azo compound was formed. The crude precipitate was filtered and dried under vacuum. Yields ranged between $30 \%$ and $40 \%$.

3'-Hydroxy-(4-hydroxy-3,5-dimethyl)-azobenzene (3a): 3-Aminophenol and 2,6-dimethylphenol were used as starting reagents. The crude product was extracted and crystallized from boiling $n$-octane $(100 \mathrm{~mL})$ and dried. Final crystallization from boiling water/ethanol (3:1) gave pure 3a as orange crystals. Polarized optical microscopy showed a needle-like crystalline form. Yield: $30 \% .{ }^{1} \mathrm{H}-\mathrm{NMR}$ (DMSO- $d_{6}$ ): $\delta(\mathrm{ppm})=7.55(\mathrm{~s}, 2 \mathrm{H}), 7.34(\mathrm{~m}, 2 \mathrm{H}), 7.19(\mathrm{~d}, 1 \mathrm{H}), 6.90(\mathrm{~d}, 1 \mathrm{H}), 2.27(\mathrm{~s}, 6 \mathrm{H})$. HPLC chromatogram of $3 \mathbf{a}$ shows a single peak, ensuring a purity $>95 \%$ (Supplementary Materials Figure S1).

4-Hydroxy-3,5-dimethylazobenzene (3b): Aniline and 2,6-dimethylphenol were used as starting reagents. The crude product was extracted and crystallized from boiling water/ethanol (3:1) and dried, to give pure $\mathbf{3 b}$ as amber crystals. Polarized optical microscopy showed a needle crystalline habitus. Yield: $35 \%{ }^{1} \mathrm{H}-\mathrm{NMR}\left(\mathrm{DMSO}-d_{6}\right): \delta(\mathrm{ppm})=7.82(\mathrm{~d}, 2 \mathrm{H}), 7.55(\mathrm{~m}, 5 \mathrm{H}), 2.27(\mathrm{~s}, 6 \mathrm{H})$. HPLC chromatogram of $3 \mathrm{~b}$ shows a single peak, ensuring a purity $>95 \%$ (Supplementary Materials Figure S2).

4'-Methoxy-(4-hydroxy-3,5-dimethyl)azobenzene (3c): p-Anisidine and 2,6-dimethylphenol were used as starting reagents. The extraction and crystallization of the crude product from boiling water/ethanol (3:1) gave pure $3 \mathbf{c}$ as yellow crystals. Polarized optical microscopy showed a needle-like crystalline form. Yield: $40 \% .{ }^{1} \mathrm{H}-\mathrm{NMR}$ (DMSO- $\left.d_{6}\right): \delta(\mathrm{ppm})=7.81(\mathrm{~d}, 2 \mathrm{H}), 7.51(\mathrm{~s}, 2 \mathrm{H}), 7.11(\mathrm{~d}, 2 \mathrm{H}), 3.85(\mathrm{~s}, 3 \mathrm{H})$, $2.26(\mathrm{~s}, 6 \mathrm{H})$. HPLC chromatogram of $3 \mathrm{c}$ shows a single peak, ensuring a purity $>95 \%$ (Supplementary Materials Figure S3).

4'-Methyl-(4-hydroxy-3,5-dimethyl)azobenzene (3d): $p$-Toluidine and 2,6-dimethylphenol were used as starting reagents. The extraction and crystallization of the crude product from boiling water/ethanol (3:1) gave pure $\mathbf{3} \mathbf{d}$ as orange crystals. Polarized optical microscopy showed a plate-like crystalline form. Yield: 38\%. ${ }^{1} \mathrm{H}-\mathrm{NMR}\left(\mathrm{DMSO}-d_{6}\right): \delta(\mathrm{ppm})=7.72(\mathrm{~d}, 2 \mathrm{H}), 7.54(\mathrm{~s}, 2 \mathrm{H}), 7.36(\mathrm{~d}, 2 \mathrm{H}), 2.39(\mathrm{~s}, 3 \mathrm{H})$, $2.27(\mathrm{~s}, 6 \mathrm{H})$. HPLC chromatogram of $\mathbf{3 d}$ shows a single peak, ensuring a purity $>95 \%$ (Supplementary Materials Figure S4).

\subsection{General Method of the Synthesis of (Phenyl-Diazenyl)Phenols Derivatives 3e-g}

A suspension of the proper aromatic amine $(0.0183 \mathrm{~mol})$ in a solution containing water $(38 \mathrm{~mL})$ and $\mathrm{HCl} 37 \%(w / w, 4 \mathrm{~mL})$ was cooled at $0-5^{\circ} \mathrm{C}$ in a water-ice bath. A solution of sodium nitrite $(1.39 \mathrm{~g}$, $0.0202 \mathrm{~mol})$ dissolved in water $(8 \mathrm{~mL})$ was added dropwise, giving a suspension of the diazonium salt (solution A). Separately, a solution containing $\mathrm{NaOH}(0.7 \mathrm{~g}, 0.0175 \mathrm{~mol})$ in water $(100 \mathrm{~mL}, \mathrm{pH}=14)$ 
with phenol (1.72 $\mathrm{g}, 0.0183 \mathrm{~mol}$ ) was prepared (solution B). Solution A was added dropwise to solution $\mathrm{B}$, under stirring at $12{ }^{\circ} \mathrm{C}$. The system was left reacting for $30 \mathrm{~min}$, maintaining the $\mathrm{pH}=11$. The final solution was slowly added to $300 \mathrm{~mL}$ of an aqueous solution of acetic acid $(\mathrm{pH}=5)$ and then stirred for $30 \mathrm{~min}$ at $15^{\circ} \mathrm{C}$. In this step, to facilitate the precipitation of the azo compound I sodium acetate powder $(0.5 \mathrm{~g})$ was added and the mixture stirred for $20 \mathrm{~min}$ in water-ice bath. A dark precipitate of the azo compound was obtained, filtered and dried under vacuum. Yields ranged between 50\% and $60 \%$.

4'-Hydroxyazobenzene (3e): Aniline and phenol were used as starting reagents. The crude product was extracted and crystallized from boiling $n$-octane $(100 \mathrm{~mL})$ and dried. Final crystallization from boiling water gave pure $3 \mathbf{e}$ as orange/yellow crystals. Polarized optical microscopy allowed the observation of needle-like crystals of the azo compound. Yield: $56 \% .{ }^{1} \mathrm{H}-\mathrm{NMR}\left(\mathrm{DMSO}-d_{6}\right): \delta(\mathrm{ppm})=7.81(\mathrm{t}, 4 \mathrm{H})$, $7.54(\mathrm{~m}, 3 \mathrm{H}), 6.96(\mathrm{~d}, 2 \mathrm{H})$. HPLC chromatogram of $3 \mathrm{e}$ shows a single peak, ensuring a purity $>95 \%$ (Supplementary Materials Figure S5).

4'-Hydroxy-4-methoxyazobenzene (3f): $p$-Anisidine and phenol were used as starting reagents. The crude product was extracted and crystallized from boiling $n$-octane $(100 \mathrm{~mL})$ and dried. Final crystallization from boiling water/ethanol (3:1) gave pure $3 \mathbf{f}$ as dark orange crystals. Polarized optical microscopy showed a plate-like crystalline form. Yield: 58\%. ${ }^{1} \mathrm{H}-\mathrm{NMR}\left(\mathrm{DMSO}-\mathrm{d}_{6}\right): \delta(\mathrm{ppm})=7.80(\mathrm{dd}, 4 \mathrm{H}), 7.51$ $(\mathrm{s}, 2 \mathrm{H}), 7.11(\mathrm{~d}, 2 \mathrm{H}), 6.93(\mathrm{~d}, 2 \mathrm{H}), 3.86(\mathrm{~s}, 3 \mathrm{H})$. HPLC chromatogram of $\mathbf{3 f}$ shows a single peak, ensuring a purity $>95 \%$ (Supplementary Materials Figure S6).

4'-Hydroxy-4-methylazobenzene (3g): $p$-Toluidine and phenol were used as starting reagents. The crude product was extracted and crystallized from boiling $n$-octane $(100 \mathrm{~mL})$ and dried. Final crystallization from boiling water/ethanol (3:1) gave pure $\mathbf{3 g}$ as brilliant yellow crystals. Polarized optical microscopy showed a needle-like crystalline form. Yield: 60\%. ${ }^{1} \mathrm{H}-\mathrm{NMR}\left(\mathrm{DMSO}-\mathrm{d}_{6}\right): \delta(\mathrm{ppm})=7.75(\mathrm{dd}, 4 \mathrm{H}), 7.54$ $(\mathrm{s}, 2 \mathrm{H}), 7.35(\mathrm{~d}, 2 \mathrm{H}), 6.93(\mathrm{~d}, 2 \mathrm{H}), 2.39(\mathrm{~s}, 3 \mathrm{H})$. HPLC chromatogram of $\mathbf{3 g}$ shows a single peak, ensuring a purity $>95 \%$ (Supplementary Materials Figure S7).

\subsection{Antimicrobial Tests}

\subsubsection{Bacterial Strains and Minimum Inhibitory Concentrations}

The in vitro minimal inhibitory concentrations (MIC) of each compound was determined against Candida albicans SC5314 by the micro-broth dilution method in 96-well plates according to the guidelines suggested by the Clinical and Laboratory Standards Institute (CLSI) [20] using three separate plates each containing the same batch of azo compounds.

Microtiter plates containing $100 \mu \mathrm{L}$ of two-fold serial dilutions of azo compounds in RPMI 1640 medium were inoculated with $100 \mu \mathrm{L}$ of cells containing $2.5 \times 10^{3}$ yeast $/ \mathrm{mL}$ and incubated at $35^{\circ} \mathrm{C}$ for $24 \mathrm{~h}$. The resulting MICs were visually read as the lowest concentration of compound causing a reduction or an absence of growth (optically clear) in comparison to the drug-free growth control.

For S. aureus A170 a clinically isolated gentamicin resistant strain (kindly provided by Prof. R. Capparelli from the University of Naples, Naples, Italy) and P. aeruginosa ATCC-27853, MIC values of each compound were determined by the serial broth microdilution method as reported by Patton [21]. Therefore, flat-bottom polystyrene microtiter plates containing $100 \mu \mathrm{L}$ of two-fold serial dilutions (six replicates per dilution) of azo compounds were inoculated with $100 \mu \mathrm{L}$ of $\sim 5 \times 10^{5} \mathrm{CFU} / \mathrm{mL}$ of each bacterium grown in Mueller-Hinton broth 2. The controls were the wells contained broth only (negative control) and bacteria and broth (positive control).

Plates were incubated at $37^{\circ} \mathrm{C}$ with shaking at $160 \mathrm{rpm}$ for $24 \mathrm{~h}$. Data were analyzed according to Patton et al. [21]. The optical density (OD) was determined just before the incubation $\left(\mathrm{T}_{0}\right)$ and again after $24 \mathrm{~h}$ incubation $\left(\mathrm{T}_{24}\right)$ at $600 \mathrm{~nm}$. The OD for each replicate at $\mathrm{T}_{0}$ was subtracted from the OD for each replicate at $\mathrm{T}_{24}$. The adjusted OD of each control well was then assigned a value of $100 \%$ growth. 
The MIC is reported as the lowest concentration of azo compounds, which results in $100 \%$ or $50 \%$ inhibition of growth.

\subsubsection{Candida Albicans Morphological Analysis}

Hyphal growth of Candida-treated cells was induced using RPMI 1640 medium. Stationary yeast cells were inoculated into a fresh pre-warmed medium at a density of $6 \times 10^{6}$ cells $/ \mathrm{mL}$ in a flat-bottom 96 well microtiter plates. Different concentrations of azo compounds (ranging from 1 to $50 \mu \mathrm{g} / \mathrm{mL}$ ), were added to each well. After incubation at $37^{\circ} \mathrm{C}$ for $24 \mathrm{~h}$, each microtiter plate was examined using an inverted microscope to monitor phenotypic modification and hyphae formation.

\subsection{QSAR Analysis}

For the series of 14 azobenzenes molecules we have calculated 3780 chemical descriptors by means of the PaDel tool [22] and the Genetic algorithms available in the program Materials Studio [23]. The 3780 parameters calculated have been standardized by range between -1 and 1 . The regression was made using the inverse of $\mathrm{MIC}_{50}$ against $S$. aureus.

The number of descriptors in the regression equation was set to 2, and Population and Generation were set to 5000 and 50,000, respectively. Mutation probability was 0.1, and the smoothing parameter was 0.5 . The choice of keeping the number of descriptors low was intended to avoid overfitting and to determine the most important molecular descriptors only, whereas all the other parameters have been chosen as recommended by the software developers. In all simulations, the algorithm reached convergence within 270 and 380 generations.

The choice of the models was based on Friedman's Lack of Fit (LOF) calculated as follows:

$$
L O F=\frac{S S E}{M\left[1-\lambda\left(\frac{c+d p}{M}\right)\right]^{2}}
$$

where SSE is the sum of squares of errors, $c$ is the number of terms in the model, other than the constant term, $d$ is a scaled smoothing parameter, $p$ is the total number of descriptors contained in all model terms (again ignoring the constant term), $M$ is the number of samples in the training set, and $\lambda$ is a safety factor, with a value of 0.99 , to ensure that the denominator of the expression can never become zero, and so the LOF is always well-defined.

An adjusted $\mathrm{R}^{2}$ estimation, where the variance is reduced in proportion to the size of the estimated model. The adjusted $\mathrm{R}^{2}$ is calculated as follows:

$$
1-\frac{S S E /(n-p)}{S S T /(n-1)}
$$

where $p$ is the number of parameters in the regression equation. SST is the total sum of squares, and $n$ is the number of data points from which the model is built. Compared to $\mathrm{R}^{2}$, this measure penalizes large equations. The cross validated $R$-squared $\left(R^{2}(C V)\right)$ value is also a key measure of the predictive power of a model. The closer the value is to 1.0 , the better the predictive power. For a good model, $\mathrm{R}^{2}(\mathrm{CV})$ should be fairly close to $R^{2}$. If $R^{2}(C V)$ is much less than $R^{2}$, the model equation is probably overfitting the data. A model with an $R^{2}(C V)$ value of 0.0 or less has no predictive power at all, according to the cross-validation criterion. The $\mathrm{R}^{2}(\mathrm{CV})$ is calculated as follows:

$$
1-\frac{P R E S S}{S S T}
$$


where PRESS is the predictive sum of squares of a model. After a required group of data is deleted, the remaining data in $x$ is used to produce a new model for $y$. These predicted values of $y$ are compared with the exact values that have been excluded:

$$
\operatorname{PRESS}(n)=\sum_{i=0}^{n}\left(y_{i}-y_{i}^{\prime}\right)^{2}
$$

A model is produced for each row or group of rows excluded. An indication of whether or not the regression is statistically significant: Yes if $\mathrm{F}>\mathrm{Fcr}$, No if not. $\mathrm{F}$ is the significance-of-regression $F$ value and For is the critical SOR $F$ value (95\%).

The $\mathrm{F}$ test is a standard statistical test for the equality of the variances of two populations having normal distributions. Here, it is used to test whether the variance in the data which is explained by the regression is much larger than the variance remaining due to errors. If this is the case, then the model is said to be significant, rather than one which simply fits the noise [24]. The significance-of-regression $F$ value is defined as:

$$
\frac{S S R /(p-1)}{\operatorname{SSE} /(n-p)}
$$

This parameter is used to determine whether or not the regression is statistically significant. The critical significance-of-regression (SOR) $F$ value is the critical point of the $F$ distribution of degrees $n-p$ and $p-1$ evaluated for probability 0.05 (at 95\% confidence level). In conjunction with the significance-of-regression $F$ value, it is used to determine whether or not the regression is significant.

\section{Conclusions}

Some novel derivatives of (4'-hydroxy-(4-hydroxy-3,5-dimethyl)azobenzene) were designed, synthesized, and biologically evaluated as antimicrobial agents. The majority of the synthesized compounds exhibited significant antibacterial activity against $S$. aureus and antifungal activity against C. albicans, but they were inactive against Gram-negative bacteria such as P. aeruginosa. The best results were obtained for 4-hydroxy-3,5-dimethylazobenzene ( $\mathbf{3 b}$ ), which showed higher antibacterial activity against $S$. aureus than lead compound. The best antifungal activity was obtained for 4 -hydroxy-4-methylazobenzene (3g) that was able to inhibit the growth of $100 \%$ of C. albicans at a concentration five times lower than the lead compound.

Structure-activity relationship studies could rationalize the effect of different substitution patterns on the phenyl ring of the azobenzene on antimicrobial activity. Changing the electronic nature and the position of the substituent group attached to the aromatic ring led to changes in the observed MIC. These observations suggest that the killing ability depends mainly by the interaction with a not yet identified receptor. The best QSAR model explains the role of polarity and ionizability in determining the killing capacity of the synthetized compounds and suggests that these molecules interact with protein receptors and that the interaction with membranes is of minor importance. The solubility and the partition coefficient may rationalize the apparent poor activity of the compound $\mathbf{3 d}$. Taken together, these results can be extremely promising for the design of novel azobenzene-based antibiotics.

Supplementary Materials: The Supplementary Materials are available online.

Acknowledgments: This research work was financially supported by the Italian Minister of Instruction, University and Research (MIUR)-300395FRB15.

Author Contributions: S. Concilio, S. Piotto and P. Iannelli designed the idea, and the protocol of the study. S. Concilio helped in synthesizing the compounds and wrote the manuscript. L. Sessa and R. Diana synthesized the compounds, wrote the experimental parts and interpreted the experimental data. S. Piotto performed the computational analysis and wrote the manuscript. A. Porta and A.M. Petrone performed the biological studies and wrote the experimental data. All the authors revised the whole manuscript.

Conflicts of Interest: The authors declare no conflict of interest. 


\section{References}

1. Ball, A.P.; Bartlett, J.G.; Craig, W.A.; Drusano, G.L.; Felmingham, D.; Garau, J.A.; Klugman, K.P.; Low, D.E.; Mandell, L.A.; Rubinstein, E.; et al. Future trends in antimicrobial chemotherapy: Expert opinion on the 43rd icaac. J. Chemother. 2004, 16, 419-436. [CrossRef] [PubMed]

2. Liu, C.; Bayer, A.; Cosgrove, S.E.; Daum, R.S.; Fridkin, S.K.; Gorwitz, R.J.; Kaplan, S.L.; Karchmer, A.W.; Levine, D.P.; Murray, B.E. Clinical practice guidelines by the infectious diseases society of america for the treatment of methicillin-resistant Staphylococcus aureus infections in adults and children. Clin. Infect. Dis. 2011, 52, e18-e55. [CrossRef] [PubMed]

3. Smith, A. Bacterial resistance to antibiotics. In Hugo and Russell's Pharmaceutical Microbiology; Blackwell, Science: 350 Main Street, Malden, MA, USA, 2004; pp. 220-223.

4. Wright, G.D. Bacterial resistance to antibiotics: Enzymatic degradation and modification. Adv. Drug Deliv. Rev. 2005, 57, 1451-1470. [CrossRef] [PubMed]

5. Stewart, P.S.; Costerton, J.W. Antibiotic resistance of bacteria in biofilms. Lancet 2001, 358, 135-138. [CrossRef]

6. Tenover, F.C. Development and spread of bacterial resistance to antimicrobial agents: An overview. Clin. Infect. Dis. 2001, 33, S108-S115. [CrossRef] [PubMed]

7. Smith, A.W. Biofilms and antibiotic therapy: Is there a role for combating bacterial resistance by the use of novel drug delivery systems? Adv. Drug Deliv. Rev. 2005, 57, 1539-1550. [CrossRef] [PubMed]

8. Jenssen, H.; Hamill, P.; Hancock, R.E. Peptide antimicrobial agents. Clin. Microbiol. Rev. 2006, 19, $491-511$. [CrossRef] [PubMed]

9. Piotto, S.; Concilio, S.; Sessa, L.; Porta, A.; Calabrese, E.C.; Zanfardino, A.; Varcamonti, M.; Iannelli, P. Small azobenzene derivatives active against bacteria and fungi. Eur. J. Med. Chem. 2013, 68, 178-184. [CrossRef] [PubMed]

10. Concilio, S.; Iannelli, P.; Sessa, L.; Olivieri, R.; Porta, A.; De Santis, F.; Pantani, R.; Piotto, S. Biodegradable antimicrobial films based on poly (lactic acid) matrices and active azo compounds. J. Appl. Polym. Sci. 2015, 132. [CrossRef]

11. Piotto, S.; Concilio, S.; Sessa, L.; Iannelli, P.; Porta, A.; Calabrese, E.C.; Galdi, M.R.; Incarnato, L. Novel antimicrobial polymer films active against bacteria and fungi. Polym. Compos. 2013, 34, 1489-1492. [CrossRef]

12. Sessa, L.; Concilio, S.; Iannelli, P.; De Santis, F.; Porta, A.; Piotto, S. Antimicrobial azobenzene compounds and their potential use in biomaterials. AIP Conf. Proc. 2016, 1727, 020018.

13. Cariati, F.; Caruso, U.; Centore, R.; De Maria, A.; Fusco, M.; Panunzi, B.; Roviello, A.; Tuzi, A. Optical second order nonlinearities in new chromophores obtained by selective mono-reduction of dinitro precursors. Opt. Mater. 2004, 27, 91-97. [CrossRef]

14. Piotto, S.; Trapani, A.; Bianchino, E.; Ibarguren, M.; López, D.J.; Busquets, X.; Concilio, S. The effect of hydroxylated fatty acid-containing phospholipids in the remodeling of lipid membranes. Biochim. Biophys. Acta Biomembr. 2014, 1838, 1509-1517. [CrossRef] [PubMed]

15. Scrima, M.; Di Marino, S.; Grimaldi, M.; Campana, F.; Vitiello, G.; Piotto, S.P.; D'Errico, G.; D'Ursi, A.M. Structural features of the $\mathrm{c} 8$ antiviral peptide in a membrane-mimicking environment. Biochim. Biophys. Acta Biomembr. 2014, 1838, 1010-1018. [CrossRef] [PubMed]

16. Concilio, S.; Bugatti, V.; Iannelli, P.; Piotto, S.P. Synthesis and characterization of new photoluminescent oxadiazole/carbazole-containing polymers. Int. J. Polym. Sci. 2010, 2010. [CrossRef]

17. Concilio, S.; Bugatti, V.; Neitzert, H.C.; Landi, G.; De Sio, A.; Parisi, J.; Piotto, S.; Iannelli, P. Zn-complex based on oxadiazole/carbazole structure: Synthesis, optical and electric properties. Thin Solid Films 2014, 556, 419-424. [CrossRef]

18. Acierno, D.; Amendola, E.; Bugatti, V.; Concilio, S.; Giorgini, L.; Iannelli, P.; Piotto, S.P. Synthesis and characterization of segmented liquid crystalline polymers with the azo group in the main chain. Macromolecules 2004, 37, 6418-6423. [CrossRef]

19. Ghose, A.K.; Viswanadhan, V.N.; Wendoloski, J.J. Prediction of hydrophobic (lipophilic) properties of small organic molecules using fragmental methods: An analysis of alogp and clogp methods. J. Phys. Chem. A 1998, 102, 3762-3772. [CrossRef]

20. CLSI, Clinical and Laboratory Standards Institute. Reference Method for Broth Dilution Antifungal Susceptibility Testing of Yeasts; Approved Standard-Third Edition; CLSI: Wayne, PA, USA, 2008; document m27-a3. 
21. Patton, T.; Barrett, J.; Brennan, J.; Moran, N. Use of a spectrophotometric bioassay for determination of microbial sensitivity to manuka honey. J. Microbiol. Methods 2006, 64, 84-95. [CrossRef] [PubMed]

22. Yap, C.W. Padel-descriptor: An open source software to calculate molecular descriptors and fingerprints. J. Comput. Chem. 2011, 32, 1466-1474. [CrossRef] [PubMed]

23. Accelrys. Accelrys Materials Studio; Accelrys Inc.: San Diego, CA, USA, 2014.

24. Todeschini, R.; Consonni, V. Molecular Descriptors for Chemoinformatics, Volume 41 (2 Volume Set); John Wiley \& Sons: Hoboken, NJ, USA, 2009.

Sample Availability: Samples of the compounds are not available from the authors.

(C) 2017 by the authors. Licensee MDPI, Basel, Switzerland. This article is an open access article distributed under the terms and conditions of the Creative Commons Attribution (CC BY) license (http:/ / creativecommons.org/licenses/by/4.0/). 